Original Research

\title{
A Preliminary Investigation of Relationships among Pharyngeal Acidity, Dysphagia, and Pneumonia in Acute Stroke
}

Aarthi Madhavan ${ }^{1,+, *}$, Isaac Sia ${ }^{2,+}$, Giselle Carnaby ${ }^{3,+}$, Michael Crary $^{3,+}$

1. Research in Aging and Dysphagia Lab, Department of Communication Sciences and Disorders, Pennsylvania State University, University Park, PA 16802, USA; E-Mail: axm1125@psu.edu

2. Department of Rehabilitation, National University Hospital, Singapore; E-Mail: Isaac sia@nuhs.edu.sg

3. Center for Upper Aerodigestive Functions, University of Central Florida, Orlando, FL 32826, USA; EMails: Giselle.carnaby@ucf.edu; Michael.crary@ucf.edu

† These authors contributed equally to this work.

* Correspondence: Aarthi Madhavan; E-Mail: axm1125@psu.edu

Academic Editor: David G Smithard

Collection: Dysphagia in the Elderly

OBM Geriatrics

2021, volume 5, issue 1

doi:10.21926/obm.geriatr.2101158
Received: October 29, 2020

Accepted: February 12, 2021

Published: February 22, 2021

\begin{abstract}
Individuals with acute stroke on nonoral feeding regimens frequently develop pneumonia, questioning the long-held belief that pneumonia in stroke patients is a caused by food and liquid aspiration alone. Refluxate and colonized oral secretions are thought to contribute to an acidic oropharyngeal environment. If aspirated, these colonized oral secretions with increased acidity, can result in increased risk to the respiratory system. This study aimed to investigate the relationship between pharyngeal acidity, dysphagia, and pneumonia in acute stroke patients. Twenty-one patients (mean age 67 years) admitted to a stroke unit were recruited into this study.
\end{abstract}

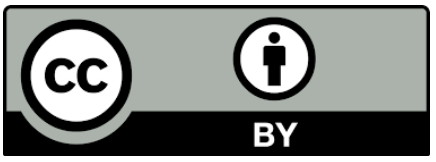

(C) 2021 by the author. This is an open access article distributed under the conditions of the Creative Commons by Attribution License, which permits unrestricted use, distribution, and reproduction in any medium or format, provided the original work is correctly cited. 
We evaluated their stroke and dysphagia severity via clinical measures. Pharyngeal acidity was measured using a Restech Dx-pH measurement probe placed transnasally for 24 hours. Sixty two (62\%) patients presented with moderate to severe stroke and $38 \%$ with dysphagia. Seven patients (33\%) were positive for pharyngeal acidity. Two patients with pharyngeal acidity were diagnosed with chest infection. Pharyngeal acidity was significantly correlated with stroke severity $(r=0.487$, $P=0.03$ ) and significantly and inversely correlated to clinical swallow performance ( $r$ ho $=-0.626$, $\mathrm{p}=0.02$ ). Additionally, pharyngeal acidity was significantly associated with categorical dysphagia scores $\left(\chi^{2}(3,21)=10.5, p<0.01\right)$, functional oral intake $\left(\chi^{2}(3,21)=15.7, p<0.001\right)$, presence of modified diets $\left(\chi^{2}(1,21)=14.0, p=0.0001\right)$, and tube feeding $\left(\chi^{2}(1,21)=9.992, p=0.002\right)$. Preliminary results suggest that acute stroke patients with dysphagia may present with increased risk for increased pharyngeal acidity. Pharyngeal acidity can result in negative sequelea, including respiratory complications. A better understanding of these potential relationships may lead to enhanced assessment and treatment approaches that limit pharyngeal acidity and resulting respiratory complications in acute stroke patients.

\section{Keywords}

Acute stroke; dysphagia; deglutition disorders; pharyngeal acidity

\section{Introduction}

Dysphagia is prevalent in acute stroke and associated with multiple co-morbidities including poor nutrition and hydration, poor oral hygiene, and infections such as pneumonia [1, 2]. Approximately $10 \%$ of acute stroke survivors develop pneumonia and these tend to be patients with larger strokes on nonoral feeding regimens [3-5]. These observations suggest that in attempting to identify causes for pneumonia in acute stroke, aspirants beyond food and liquid should be considered. Colonized secretions and refluxate material are potential aspirants that might contribute to pneumonia in this population. Both of these potential aspirants may contribute to increased pharyngeal acidity, thus increasing the risk of respiratory system damage leading to infection [6].

The healthy pharyngeal environment is non-acidic $[7,8]$. Acute stroke patients may be at elevated risk of increased pharyngeal acidity due to factors such as bacterial colonization, reduced oral hygiene, and reflux [9-11]. Furthermore, dysphagia may contribute to increased pharyngeal acidity through impaired oropharyngeal clearance [12-14]. The presence of acid-producing bacteria is normal in the oral cavity [15-19]. Salivary clearance via swallowing, mastication, and oral hygiene help remove these bacteria in the healthy adult [15]. In stroke patients, these processes are often compromised, creating the potential for an increased acidic environment in the pharyngeal region. Gastric reflux is another potential contributor to increased pharyngeal acidity [20-23]. Supraesophageal reflux has been associated with negative respiratory outcomes including bronchopulmonary disorders, recurrent pneumonia, chronic cough, and chronic or recurrent laryngitis [24]. Such findings indicate that the respiratory tract is highly vulnerable to acidic insult and highlight the importance of detecting increased 
pharyngeal acidity in individuals at risk for respiratory disease. Finally, acute stroke patients are at increased risk for poor oral hygiene due to impaired self-care secondary to cognitive impairments and/or limitations in upper limb function [25].

Collectively, the prevalence of dysphagia and related limitations in acute stroke may support an oropharyngeal environment of enhanced acidity; however, potential relationships between these swallowing functions and pharyngeal acidity have not been demonstrated. Furthermore, although the airway is known to be sensitive to acidic insult, the impact of increased pharyngeal acidity on respiratory complications in acute stroke is unclear.

This study assessed the prevalence of pharyngeal acidity in a cohort of acute stroke patients and examined potential relationships among pharyngeal acidity, stroke severity, dysphagia, and oral intake in patients with acute stroke. In addition, we evaluated potential associations between pharyngeal acidity and the development of chest infection in acute stroke. We hypothesized that modified diets would increase pharyngeal acidity in acute stroke individuals. Additionally, we hypothesized that increased pharyngeal acidity would be associated with increased respiratory complications.

\section{Materials and Methods}

\subsection{Participants}

Twenty-one acute ischemic stroke (AIS) patients admitted to the stroke service at an academic medical center over a 6-month period participated in this study. All patients were enrolled into the study within 72 hours of hospital admission and had stroke diagnosis confirmed by both neurological and radiological examinations. Patients were excluded if they had any history of connective tissue disease (e.g. lupus, scleroderma), esophageal surgery, respiratory disease (e.g. asthma, COPD), or unresolved oropharyngeal or esophageal dysphagia from previous/comorbid diseases or conditions (e.g. head and neck cancer, esophageal cancer, neurological diseases). In addition, patients on mechanical ventilation or who were pregnant were excluded.

\subsection{Ethics Statement}

The local Institutional Review Board reviewed and approved the study. Patients (or their legal representatives) who agreed to participate in the study signed approved consent forms prior to enrollment.

\subsection{Data Collection}

Patient histories were obtained from electronic medical records upon study enrollment. All patients then received clinical stroke evaluations, dysphagia evaluations, and pharyngeal pH evaluations. Information on current medications were also recorded. 


\subsection{Stroke Severity}

Stroke severity was measured by the National Institutes of Health Stroke Scale (NIHSS) [26, 27] and the Modified Rankin Scale (mRS) [28, 29]. Both scales were administered within one day of study enrollment. A score of 4 was used to dichotomize NIHSS scores into mild vs moderate-severe stroke $[26,27]$. $m R S$ scores were used to describe severity of disability $[28,29]$.

\subsection{Dysphagia Evaluations}

Dysphagia evaluations were also completed within one day of enrollment for all patients. Clinical evaluation of swallowing function was completed using the Mann Assessment of Swallowing Ability (MASA) [30]. On this standardized clinical assessment of dysphagia, a score less than or equal to 178 (from a total of 200) identifies patients with dysphagia. For the purpose of this study dysphagia was treated as a dichotomous variable based on this cut point. Dysphagia severity was categorized according to total score ranges previously established: mild $=168-177$, moderate $=139-167$, severe $=<138$ [30]. The Functional Oral Intake Scale (FOIS) [31] was employed to document the amount and type or oral diet. The FOIS is a 7-point validated scale documenting the type and amount of safe and adequate oral intake. When dichotomized for specific comparisons, a score below 6 was used to reflect limitations in oral intake of food, and a score below 4 was used to identify patients on tube-feeding [31].

\subsection{Pharyngeal pH Evaluation}

Pharyngeal $\mathrm{pH}$ evaluation was completed within 24 hours of clinical evaluations (stroke and dysphagia). The detection of abnormal pharyngeal acidity utilized the Dx-pH Measurement System with automated analysis of $\mathrm{pH}$ data using DataView Lite software (Respiratory Technology Corporation (Restech), San Diego, CA) [32, 33]. The pH probe of this system senses and records both aerosolized and liquid $\mathrm{pH}$ levels and does not require constant mucosal contact for detection. The probe was placed transnasally with the sensor placed at a level $5-10 \mathrm{~mm}$ below the uvula. The position of the sensor was confirmed by observing the light-emitting diode (LED) located at the probe tip via transoral examination. Once the position was confirmed, the catheter was secured to the subject's nose and cheek using surgical tape. Pharyngeal pH was monitored for up to 24 hours [32, 34].

Mealtimes were marked for exclusion from pharyngeal $\mathrm{pH}$ analysis, including 5-minute windows before and after mealtimes. Practical limitations precluded documenting every change in patient body position (i.e. sitting upright vs. lying down) over the evaluation period. However, given the nature of the acute stroke population, patients were assumed to be lying inclined in bed for most, if not all, of the evaluation period. As such, normative thresholds for recumbent/supine position were used and pharyngeal $\mathrm{pH}$ values below baseline to a cutoff level of $\mathrm{pH}=5.0$ were identified [35]. From each $\mathrm{pH}$ recording the following measures were obtained: mean duration of episodes with $\mathrm{pH}<5.0$, total duration of all episodes with $\mathrm{pH}<5.0$, percent time where $\mathrm{pH}<5.0$ (compared to the total evaluation period), number of pharyngeal $\mathrm{pH}$ episodes with $\mathrm{pH}<5.0$ over the evaluation period, and duration of the longest episode with $\mathrm{pH}<5.0$. The RYAN score was used as the index of pharyngeal acidity. RYAN 
score was computed as the composite of percent time where $\mathrm{pH}<5.0$, number of acid events, and the longest duration of $\mathrm{pH}<5$. RYAN scores $>6.8$ were identified as being positive for pharyngeal acidity [35].

\subsection{Identification of Chest Infection/Pneumonia}

Presence of in-hospital chest infection was determined by physician diagnosis and daily review of the electronic medical records using published criteria for pneumonia following stroke $[5,10]$. To be considered positive for pneumonia, patients demonstrated three or more of the following characteristics: fever $\left(>38^{\circ} \mathrm{C}\right)$, productive cough with purulent sputum, abnormal respiratory examination (tachypnea >22 per minute, tachycardia, inspiratory crackle, bronchial breathing), abnormal chest radiographic findings, arterial hypoxemia ( $\mathrm{PO} 2<70 \mathrm{mmHg}$ or $\mathrm{SpO} 2<94 \%$ ), and isolation of a relevant pathogen (positive Gram's stain and culture).

\subsection{Statistical Analyses}

All variables were reviewed for descriptive analysis. Baseline variables for NIHSS, MASA score and Ryan score were log transformed due to positive skew. Chi-square and bivariate correlation statistics examined relationships among variables of interest. The non-parametric spearman Rho was applied where small numbers or skewed distributions remained. Comparisons between grouped variables were completed with t-tests or their nonparametric equivalent (Mann Whitney U). Significance level was set at $p<0.05$. All statistics were completed using SPSS $v 24.0$ [36].

\section{Results}

\subsection{Descriptive Results}

The cohort included 16 men and had a mean age of 67yrs (SD=13). Time to admission from stroke onset was 0.5 days (SD 1.3). Sixty-two percent (62\%) of patients presented with moderate to severe stroke (NIHSS>4); $38 \%$ with dysphagia (MASA $\leq 178$ ); $24 \%$ on modified oral diets (FOIS 4 or 5); and $19 \%$ on tube feeding (FOIS $<4)$. At the time of evaluation, seven of the twenty-one patients were on acid suppression medications, 18 were on antipyretics, and 5 were on antibiotics.

Table 1 Descriptive results for clinical measures and RYAN score.

\begin{tabular}{|c|c|c|}
\hline Measure & Mean (SD) & Rates \\
\hline NIHSS & 7.62 (SD 6.99) & $62 \%$ moderate to severe stroke (NIHSS $>4$ ) \\
\hline MASA & 172.6 (SD 26.0) & $38 \%$ with dysphagia (MASA<178) \\
\hline FOIS & 5.29 (SD 2.4) & $\begin{array}{l}24 \% \text { on modified oral diets (FOIS } 4 \text { or } 5 \text { ) } \\
19 \% \text { on tube feeding }(\text { FOIS }<4)\end{array}$ \\
\hline RYAN Score & 15.55 (SD 38.39) & $33 \%$ positive for pharyngeal acidity (RYAN > 6.8) \\
\hline
\end{tabular}

Notes: NIHSS (National Institutes of Health Stroke Scale), MASA (Mann Assessment of Swallowing Ability), FOIS (Functional Oral Intake Scale), RYAN score (index of pharyngeal acidity) 
Median duration of pharyngeal $\mathrm{pH}$ evaluation was 20.8 hours (IQR=13.1 hours). Six patients inadvertently removed the $\mathrm{pH}$ catheter while asleep, reducing total surveillance time. Seven patients (33\%) patients were positive for pharyngeal acidity (RYAN score>6.8). None of the remaining patients demonstrated any evidence of abnormal pharyngeal acidity (zero values for all measures).

\subsection{Relationships and Associations between Pharyngeal Acidity, Stroke Severity, and Swallowing Functions}

Pharyngeal acidity was significantly correlated to stroke severity (NIHSS: $r=0.487, p=0.03$ ), and significantly associated with higher NIHSS dichotomized scores $\left(\chi^{2}(1,21)=9.88, p=0.002\right)$ (Figure 1$)$. Pharyngeal acidity was also significantly and inversely correlated to clinical swallow performance (MASA: rho $=-0.626, p=0.02$ ) and significantly associated with dysphagia severity reflected in categorical MASA scores $\left(\chi^{2}(3,21)=10.5, p<0.01\right)$. Finally, pharyngeal acidity was significantly associated with functional swallow level (FOIS: $\left.\chi^{2}(3,21)=15.7, p<0.001\right)$, presence of modified diets $\left(\chi^{2}(1,21)=14.0, p=0.0001\right)$ (Figure 2$)$ and tube feeding $\left(\chi^{2}(1,21)=9.992, p=0.002\right.$ (Figure 3).

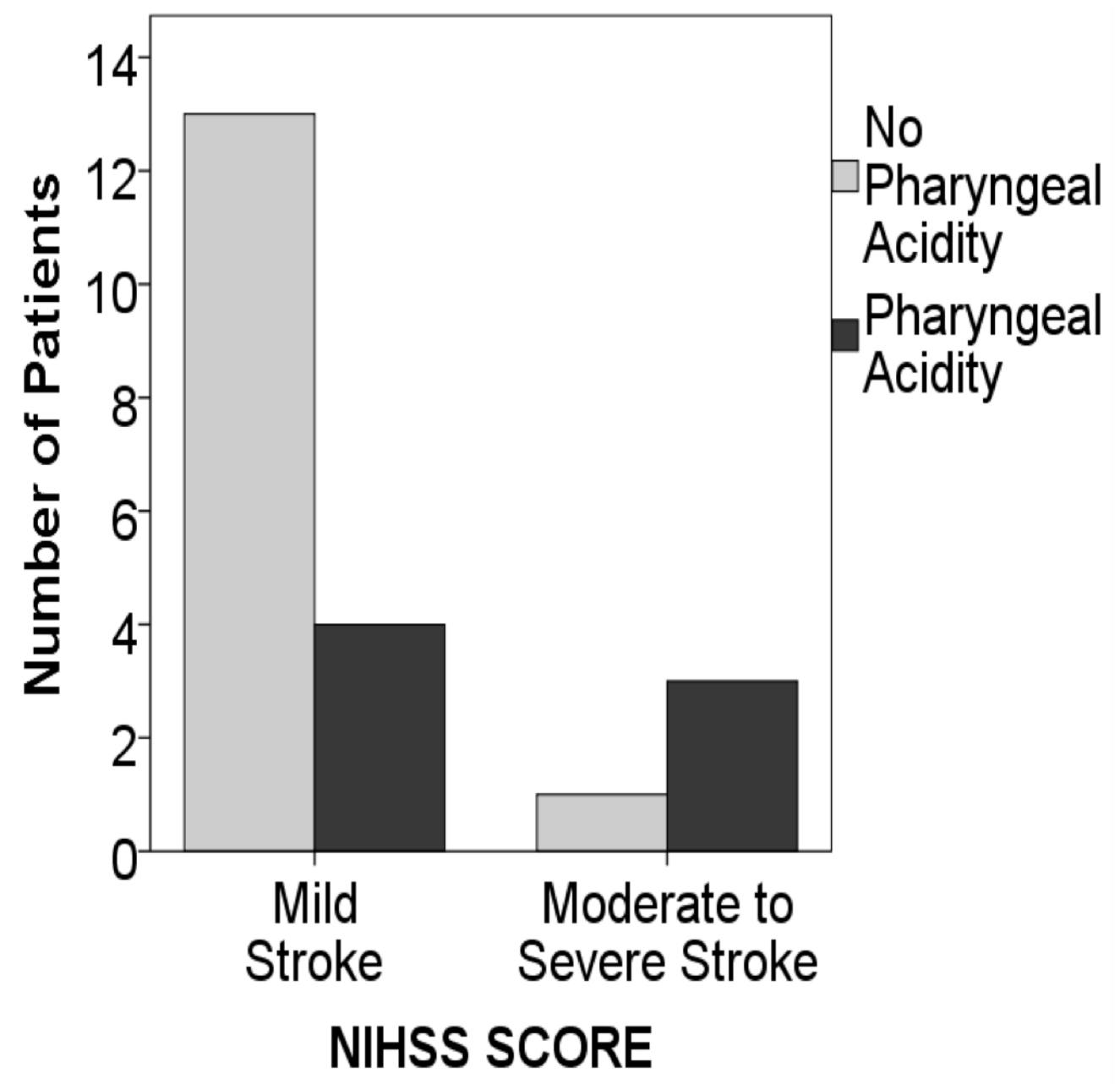

Figure 1 Pharyngeal acidity by stroke severity. 


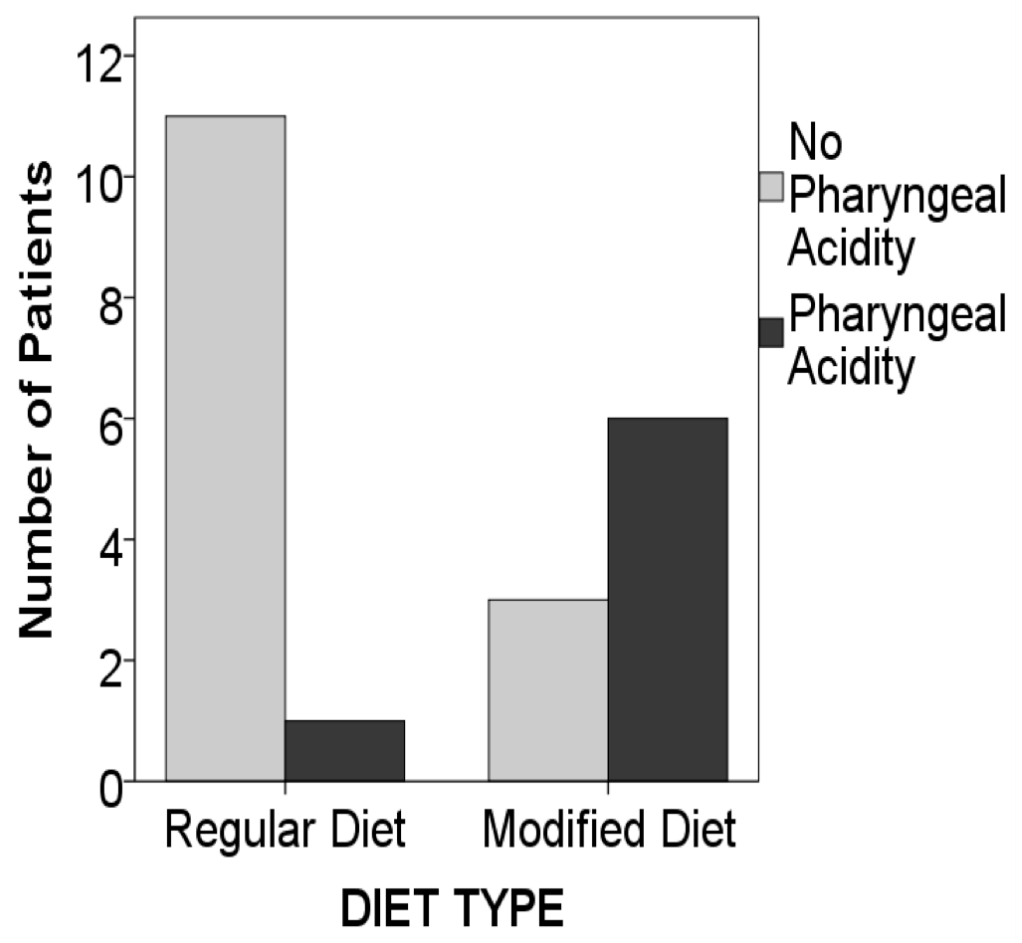

Figure 2 Pharyngeal acidity by diet type.

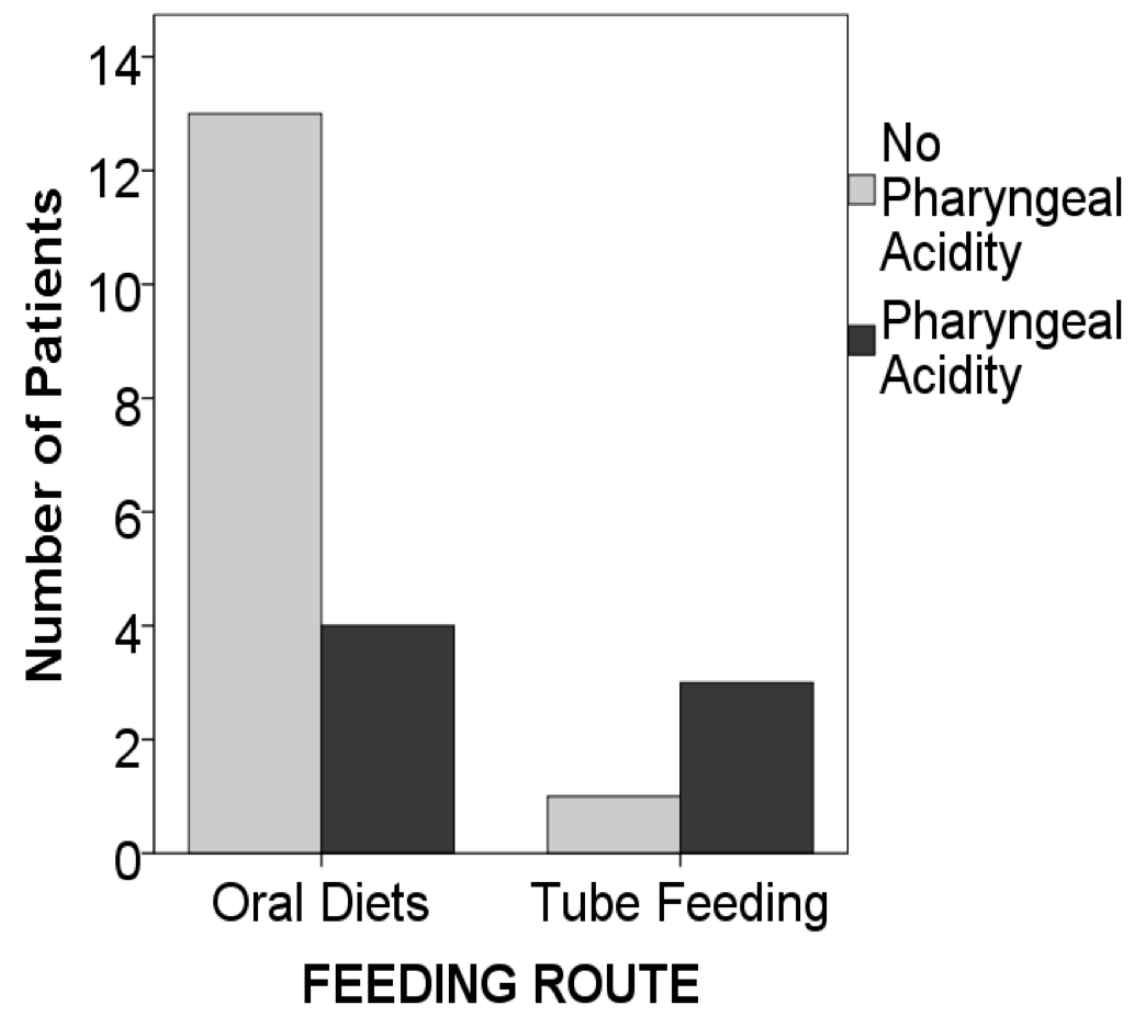

Figure 3 Pharyngeal acidity by feeding route. 


\subsection{Chest Infection}

Two patients met pre-determined criteria for chest infection (10\%). Both were positive for pharyngeal acidity (RYAN score $>6.8$ ). One of these patients had a moderate - severe stroke with an NIHSS score of 17. However, both had mRS scores of 4 and 5, indicating moderate-severe disability. Both patients were on modified diets (FOIS $<6$ ), one was tube fed, and both demonstrated dysphagia (MASA $\leq 178$ ).

Two additional patients were positive for 2 of the required 3 criteria for pneumonia and were classified as probable chest infection. One of these cases was positive for pharyngeal acidity and the other was not. These two patients with probable chest infection also demonstrated moderate to severe strokes based on NIHSS scores of 4 and 21 and mRS scores of 4 and 5 . Both patients were also on modified diets (FOIS $<6$ ), one was tube fed, and one had moderately severely dysphagia based on the MASA (MASA score 151).

\section{Discussion}

Pharyngeal acidity was related to increased stroke severity and impaired swallowing function in acute ischemic stroke (AIS) patients. Moreover, pharyngeal acidity was associated with modified diets and tube feeding. Finally, despite our small sample size, given a chest infection rate of $10 \%$, results suggest a possible role of pharyngeal acidity in chest infection for AIS patients. A combination of these results suggests a need for further investigation with larger studies.

Stroke severity has been associated with xerostomia [37], which can increase the acid environment in the oropharyngeal region. Furthermore, colonization of acid-producing bacteria is increased during the acute phase of stroke $[11,38]$. Physical weakness, lack of coordination, and cognitive deficits may limit the ability of stroke patients to self-maintain oral hygiene [39] and adequate oral care may not always be provided in acute stroke units $[40,41]$. Thus, increased stroke severity may contribute to increased pharyngeal acidity via mechanisms of increased oropharyngeal colonization and reduced oral hygiene.

Swallowing dysfunction (i.e. dysphagia) is common in acute stroke and patients with more severe stroke are more likely to present with dysphagia [1, 42]. In the present study, pharyngeal acidity was inversely correlated to dysphagia severity indicating that patients with more severe dysphagia presented the highest pharyngeal acidity levels. One possible explanation for this relationship is that patients with more severe dysphagia present with reduced oropharyngeal clearing mechanisms. For example, the frequency of spontaneous swallowing has been shown to be strongly related to severity of dysphagia in acute stroke [14]. Spontaneous swallowing is recognized as a reflexive activity that functions as an airway protection mechanism by clearing the oropharynx of pooled secretions, refluxate, and other potentially harmful materials. Thus, reduced oropharyngeal clearance associated with more severe dysphagia may be contributing to increased pharyngeal acidity in acute stroke patients.

Acidogenic (i.e. acid-producing) bacteria such as lactobacilli and bifidobacteria are resident in the oral cavity [15]. Saliva contains proteins and peptides involved in numerous antimicrobial activities e.g. agglutination, bactericide, bacteristasis (i.e. inhibiting bacterial growth) and anti-adhesion. As saliva

flushes the oral and pharyngeal cavities [43] and is subsequently swallowed [15], the unrestricted 
growth of acidogenic bacteria is prevented. Taste, smell, the sight of food and mastication of solids foods are triggers of saliva production [44]. Salivary flow rate is increased with a regular diet requiring considerable mastication [45-47]. Patients on diets requiring less mastication produce less acidneutralizing saliva during meals $[48,49]$. Thus, no oral diet, or a modified oral diet would result in less mastication and potentially reduced saliva production and related oropharyngeal clearance of acidogenic bacteria. This may at least partially explain the association between modified diets and pharyngeal acidity. Nonoral tube fed AIS patients are deprived of all major stimulants for normal saliva production and may be at greater risk for pharyngeal acidity. Moreover, pathogenic colonization of the oropharynx have been associated with nonoral tube feeding in stroke [50]. Hence, pharyngeal acidity in nonoral tube feeding patients may be related to both reduced salivary flow from the lack of oral intake and increased bacterial colonization. Collectively, the current results suggest that diet restriction of any kind may impose a risk for pharyngeal acidity in AIS patients.

This study did not include results from combined multichannel intraluminal impedance and $\mathrm{pH}$ measurement ( $\mathrm{MII}-\mathrm{pH})$ and the contribution of gastric reflux to pharyngeal acidity remains uncertain. However, univariate results from this preliminary study indicate the need for future clarifying research on the relationship between pharyngeal acidity, stroke severity, and diet modifications. Pharyngeal acidity was present in one-third of acute stroke subjects in the present study. In addition, stroke severity, swallowing impairment and diet restriction were identified as potential contributors to pharyngeal acidity. Additionally, 3 of the 4 patients diagnosed with pneumonia or probable chest infection had high pharyngeal acidity. Moreover, standard clinical care practices could have influenced surveillance of outcome variables, as several patients were on medications for acid suppression, antipyretics, and antibiotics.

Limitations of this study include a small sample size, restricting analyses to univariate relationships and associations. Additionally, some potential for bias exists as the same speech pathologist evaluated dysphagia and placed the transnasal probe. However, measurements from the trasnnasal probe are quantitative and not subject to significant interpretation bias. Additionally, evaluations of the patient's neurologic and respiratory status were obtained from medical records. Due to the small sample size, we did not have sufficient cases to support investigation of existing medical care, like medications, however, larger sample sizes might shed some light on this relationship.

Clinically, a combination of risk factors related to AIS, dysphagia, and management practices of modified diets and tube feeding may put AIS patients at risk of increased pharyngeal acidity. In our preliminary results, a possible relationship was observed between increased pharyngeal acidity and respiratory complications. Though the sample in this study was small, and the statistics limited to univariate relations and associations, these results provide preliminary support for further, larger studies of the prevalence, associated factors, and potential complications of pharyngeal acidity in acute stroke. If a larger study supports the current results, then clinical care issues such as enhanced oral care and intensive dysphagia management, leading to diet advancement, may be useful strategies to help reduce pharyngeal acidity and may result in lower pneumonia rates. 


\section{Conclusions}

Preliminary investigation of pharyngeal acidity and dysphagia in acute stroke suggests that pharyngeal acidity is related to impaired swallowing, including modified diets and tube feeding. Pharyngeal acidity may also be associated with increased stroke severity. Most importantly, pharyngeal acidity may play a role in chest infection in patients with acute ischemic stroke. Early identification and intervention to reverse the effects of these factors in acute stroke patients may be important for preventing pharyngeal acidity and its potential complications. These interventions may target reduction of disabilities in self-care leading toward improved oral hygiene and rehabilitation of swallowing function, as well as restoration of oral feeding and establishing a regular diet. Finally, a better understanding of potential relationships between pharyngeal acidity and respiratory complications in acute stroke may lead to enhanced assessment and treatment approaches that may limit these respiratory complications.

\section{Author Contributions}

AM: data analysis, writing, and revision; IS: data collection and writing; GC: conception, data analysis, writing, and revision; MC: conception, experimental design, data analysis, and writing.

\section{Funding}

UF Health Shands Quasi Endowment Fund funded this study. Respiratory Technology Corporation (Restech, San Diego, CA) provided the Dx-pH Measurement System on loan.

\section{Competing Interests}

The authors have declared that no competing interests exist.

\section{References}

1. Mann G, Hankey GJ. Initial clinical and demographic predictors of swallowing impairment following acute stroke. Dysphagia. 2001; 16: 208-215.

2. Crary MA, Humphrey JL, Carnaby-Mann G, Sambandam R, Miller L, Silliman S. Dysphagia, nutrition, and hydration in ischemic stroke patients at admission and discharge from acute care. Dysphagia. 2013; 28: 69-76.

3. Singh S, Hamdy S. Dysphagia in stroke patients. Postgrad Med J. 2006; 82: 383-391.

4. Armstrong JR, Mosher BD. Aspiration pneumonia after stroke: Intervention and prevention. Neurohospitalist. 2011; 1: 85-93.

5. Mann G, Hankey GJ, Cameron D. Swallowing function after stroke: Prognosis and prognostic factors at 6 months. Stroke. 1999; 30: 744-748.

6. Langmore SE, Terpenning MS, Schork A, Chen Y, Murray JT, Lopatin D, et al. Predictors of aspiration pneumonia: How important is dysphagia? Dysphagia. 1998; 13: 69-81.

7. Chheda NN, Seybt MW, Schade RR, Postma GN. Normal values for pharyngeal pH monitoring. Ann 
Otol Rhinol Laryngol. 2009; 118: 166-171.

8. Sun G, Muddana S, Slaughter JC, Casey S, Hill E, Farrokhi F, et al. A new pH catheter for laryngopharyngeal reflux: Normal values. Laryngoscope. 2009; 119: 1639-1643.

9. Scannapieco FA. Pneumonia in nonambulatory patients: The role of oral bacteria and oral hygiene. J Am Dent Assoc. 2006; 137: S21-25.

10. Sellars C, Bowie L, Bagg J, Sweeney MP, Miller H, Tilston J, et al. Risk factors for chest infection in acute stroke: A prospective cohort study. Stroke. 2007; 38: 2284-2291.

11. Millns B, Gosney $\mathrm{M}$, Jack $\mathrm{Cl}$, Martin MV, Wright AE. Acute stroke predisposes to oral gram-negative bacilli-a cause of aspiration pneumonia? Gerontology. 2003; 49: 173-176.

12. Martin-Harris B, Cherney LR. Treating swallowing disorders following stroke. Top Stroke Rehabil. 1996; 3: 27-40.

13. Nilsson $\mathrm{H}$, Ekberg $\mathrm{O}$, Olsson $\mathrm{R}$, Hindfelt B. Dysphagia in stroke: A prospective study of quantitative aspects of swallowing in dysphagic patients. Dysphagia. 1998; 13: 32-38.

14. Crary MA, Carnaby GD, Sia I. Spontaneous swallow frequency compared with clinical screening in the identification of dysphagia in acute stroke. J Stroke Cerebrovasc Dis. 2014; 23: 2047-2053.

15. Haukioja A. Probiotic lactobacilli and bifidobacteria in the mouth - in vitro studies on salivamediated functions and acid production. Turku, Finland: Department of Cariology and the Postgraduate School of Oral Health Sciences (PeGaSOS), University of Turku; 2009.

16. Ahrne S, Nobaek S, Jeppsson B, Adlerberth I, Wold AE, Molin G. The normal Lactobacillus flora of healthy human rectal and oral mucosa. J Appl Microbiol. 1998; 85: 88-94.

17. Colloca ME, Ahumada MC, Lopez ME, Nader-Macias ME. Surface properties of lactobacilli isolated from healthy subjects. Oral Dis. 2000; 6: 227-233.

18. Maukonen J, Mättö J, Suihko ML, Saarela M. Intra-individual diversity and similarity of salivary and faecal microbiota. J Med Microbiol. 2008; 57: 1560-1568.

19. Simark-Mattsson C, Emilson CG, Håkansson EG, Jacobsson C, Roos K, Holm S. Lactobacillusmediated interference of mutans streptococci in caries-free vs. caries-active subjects. Eur J Oral Sci. 2007; 115: 308-314.

20. Wilshire $\mathrm{CL}$, Galey KM, Watson TJ, Jones CE, Raymond D, Litle VR, et al. Pharyngeal pH monitoring may be superior to proximal $\mathrm{pH}$ monitoring in the detection of laryngopharyngeal reflux. Gastroenterology. 2011; 140: S-1035.

21. Jungheim $M$, Ptok $M$. Extraesophageal reflux. Overview and discussion of a new method for $\mathrm{pH}$ monitoring. HNO. 2011; 59: 893-899.

22. Pacheco-Galván A, Hart SP, Morice AH. Relationship between gastro-oesophageal reflux and airway diseases: The airway reflux paradigm. Arch Bronconeumol. 2011; 47: 195-203.

23. Wiener GJ, Tsukashima R, Kelly C, Wolf E, Schmeltzer M, Bankert C, et al. Oropharyngeal pH monitoring for the detection of liquid and aerosolized supraesophageal gastric reflux. J Voice. 2009; 23: 498-504.

24. Close LG. Laryngopharyngeal manifestations of reflux: Diagnosis and therapy. Eur J Gastroenterol Hepatol. 2002; 14: S23-27.

25. Lawrence ES, Coshall C, Dundas R, Stewart J, Rudd AG, Howard R, et al. Estimates of the prevalence of acute stroke impairments and disability in a multiethnic population. Stroke. 2001; 32: 1279-1284. 
26. Goldstein LB, Samsa GP. Reliability of the national institutes of health stroke scale: Extension to non-neurologists in the context of a clinical trial. Stroke. 1997; 28: 307-310.

27. Ortiz GA, L. Sacco R. National institutes of health stroke scale (NIHSS). In Wiley StatsRef: Statistics reference online. Hoboken, NJ: John Wiley \& Sons, Ltd.; 2014.

28. Rankin J. Cerebral vascular accidents in patients over the age of 60: II. Prognosis. Scott Med J. 1957; 2: 200-215.

29. Farrell B, Godwin J, Richards S, Warlow C. The United Kingdom transient ischaemic attack (UK-TIA) aspirin trial: Final results. J Neurol Neurosurg Psychiatry. 1991; 54: 1044-1054.

30. Mann G. MASA: The mann assessment of swallowing ability. Clifton Park, NY: Singular/Thomson Learning; 2002.

31. Crary MA, Mann GD, Groher ME. Initial psychometric assessment of a functional oral intake scale for dysphagia in stroke patients. Arch Phys Med Rehabil. 2005; 86: 1516-1520.

32. Wiener GJ, Tsukashima R, Kelly C, Wolf E, Schmeltzer M, Bankert C, et al. Dx-pH measurement system: A sensitive device for detecting liquid and aerosolized supraesophageal gastric reflux (SEGR). Gastroenterology. 2006; 130: A115.

33. Wiener GJ, Tsukashima R, Kelly C, Wolf E, Schmeltzer M, Bankert C, et al. Oropharyngeal pH monitoring for the detection of liquid and aerosolized supraesophageal gastric reflux. J Voice. 2009; 23: 498-504.

34. Sun G, Muddana S, Slaughter JC, Casey S, Hill E, Farrokhi F, et al. A new pH catheter for laryngopharyngeal reflux: Normal values. Laryngoscope. 2009; 119: 1639-1643.

35. Ayazi S, Lipham JC, Hagen JA, Tang AL, Zehetner J, Leers JM, et al. A new technique for measurement of pharyngeal pH: Normal values and discriminating pH threshold. J Gastrointest Surg. 2009; 13 : 1422-1429.

36. IBM Corp. IBM SPSS Statistics for Windows, Version 24.0. Armonk, NY: IBM Corp; 2016.

37. Kerr GD, Sellars C, Bowie L, Bagg J, Sweeney MP, Langhorne P, et al. Xerostomia after acute stroke. Cerebrovasc Dis. 2009; 28: 624-626.

38. Zhu HW, McMillan AS, McGrath C, Li LS, Samaranayake LP. Oral carriage of yeasts and coliforms in stroke sufferers: A prospective longitudinal study. Oral Dis. 2008; 14: 60-66.

39. Arai K, Sumi Y, Uematsu H, Miura H. Association between dental health behaviours, mental/physical function and self-feeding ability among the elderly: A cross-sectional survey. Gerodontology. 2003; 20: 78-83.

40. Talbot A, Brady M, Furlanetto DL, Frenkel H, Williams BO. Oral care and stroke units. Gerodontology. 2005; 22: 77-83.

41. Kwok C, Mclntyre A, Janzen S, Mays R, Teasell R. Oral care post stroke: A scoping review. J Oral Rehabil. 2015; 42: 65-74.

42. Langdon C. Dysphagia and respiratory infections in acute ischemic stroke. Australia: Acute Ischemic Stroke; 2012.

43. Cole MF, Lydyard PM. Oral microbiology and the immune response. Washington DC: American Society for Microbiology; 2006.

44. Pedersen AM, Bardow A, Jensen SB, Nauntofte B. Saliva and gastrointestinal functions of taste, mastication, swallowing and digestion. Oral Dis. 2002; 8: 117-129. 
45. Johnson DA, Sreebny LM. Effect of increasing the bulk content of the diet on the rat parotid gland and saliva. J Dent Res. 1982; 61: 691-696.

46. De Muñiz BR, Maresca BM, Tumilasci OR, Perec CJ. Effects of an experimental diet on parotid saliva and dental plaque $\mathrm{pH}$ in institutionalized children. Arch Oral Biol. 1983; 28: 575-581.

47. Dodds MW, Johnson DA. Influence of mastication on saliva, plaque $\mathrm{pH}$ and masseter muscle activity in man. Arch Oral Biol. 1993; 38: 623-626.

48. Dodds MW, Johnson DA, Yeh CK. Health benefits of saliva: A review. J Dent. 2005; 33: 223-233.

49. Johansson I, Ericson T. Effects of a 900-kcal liquid or solid diet on saliva flow rate and composition in female subjects. Caries Res. 1989; 23: 184-189.

50. Leibovitz A, Plotnikov G, Habot B, Rosenberg M, Segal R. Pathogenic colonization of oral flora in frail elderly patients fed by nasogastric tube or percutaneous enterogastric tube. J Gerontol A Biol Sci Med Sci. 2003; 58: M52-M55.

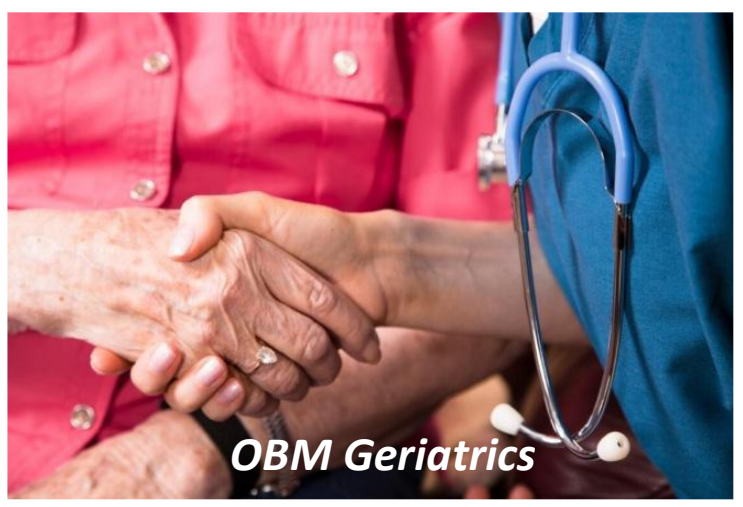

Enjoy OBM Geriatrics by:

1. Submitting a manuscript

2. Joining in volunteer reviewer bank

3. Joining Editorial Board

4. Guest editing a special issue

For more details, please visit: http://www.lidsen.com/journals/geriatrics 